6. Lin Frank Cheau-Feng, Li Ruei-Yun, Tung Yung-Wei, et al. (2016), "Morbidity, mortality, associated injuries, and management of traumatic rib fractures", Journal of the Chinese Medical Association, 79(6), 329-334.

7. Moore2 Michelle Kim1 \& James E. (2020), "Chest Trauma: Current Recommendations for Rib
Fractures, Pneumothorax, and Other Injuries", Springer Science+Business Media, LLC, part of Springer Nature 2020.

8. Zhang J. P., Sun L., Li W. Q., et al. (2019), "Surgical treatment ofpatients with severe non-flail chest rib fractures", World J Clin Cases, 7(22), 3718-3727.

\title{
ĐÁNH GIÁ KẾT QUẢ ĐÎ̀̀U TRI NGOẠI KHOA HộI CHỨNG ĐộNG MẠCH CHỦ NGỰC CẤP
}

\author{
Nông Hữu Thọ ${ }^{1}$, Phạm Thọ Tuấn Anh², Nguyễn Hoàng Định²
}

\section{TÓM TẮT}

Mục tiêu: Đánh giá kết quả điều trị ngoại khoa hội chứng ĐMC ngực cấp ở nhóm bệnh nhân được nghiên cứu. Đối tượng và phương pháp: Mô tả tiển cứu, hàng loạt các trường hợp bệnh nhân có HCĐMC ngực cấp được điều trị ngoại khoa tai khoa phẫu thuật tim, bệnh viện Chợ Rẫy và khoa phẫu thuật tim mạch, bênh viên Đai Học $Y$ Dược trong thời gian từ tháng 9/2015 đến tháng 9/2018. Kết quả: Trong thời gian 3 năm (9/2015-9/2018), chúng tôi thu thập được 102 trường hợp được chẩn đoán hội chứng ĐMC cấp. Sau khi được hội chẩn tim mạch, có 101 ca được điều trị phẫu thuật. Phân tângđược các tổn thương và xác định pham vi can thiệp: thay ĐMC lên và quai: có tỷ lệ cao nhất $(54,5 \%)$; thay ĐMC lên và bán quai: có tỷ lể ít nhất $(20,8 \%)$; xử trí thay 1 đoạn ĐMC đơn thuân là thường gặp $(24,8 \%)$; trong đó chỉ có 6 TH được phẫu thuật kêt hợp can thiệp nội mạch. Tỷ lệ tử vong sớm trong thời gian nằm viện là $22,7 \%$ (23/101). Nguyên nhân tử vong sớm: thường gặp là viêm phổi và TBMMN. Biến chứng thường gặp nhất: TBMMN $(25,7 \%)$, viêm phổi $(37,6 \%)$. Kết quả trung hạn: thời gian theo dõi trung bình là 32,2 tháng. Ghi nhận: có 8 trường hợp mất dấu theo dõi và có thêm 7 TH tử vong trong suốt thời gian theo dõi. Tỷ lệ sống còn của nghiên cứu theo đồ thi Kaplan-Meier là: 69\%. Kết luận: Điều trị phẫu thuật vấn còn nhiều khó khăn và thử thách. Pham vi xử trí tập trung đoan lên và quai chiếm tỷ lệ cao. Thay ĐMC lên và quai $(54,5 \%)$; thay ĐMC lên và bán quai $(20,8 \%)$. Nhiều biến chứng sau mổ được ghi nhận với tỷ lệ khác nhau. Tỷ lệ tử vong sớm trong thời gian nằm viện là $22,7 \%$. Trong suốt thời gian theo dỗi là 32,2 tháng, tỷ lệ sống còn theo đồ thi Kaplan- Meier là 69\%.

Từ khóa: Hội chứng ĐMC cấp, Bóc tách ĐMC, Huyết khối tụ thành, Loét xuyên thành, phình ĐMC dọa võ.

\section{SUMMARY \\ EVALUATING THE RESULTS OF SURGICAL}

${ }^{1}$ Bênh viên Quân y 175

2Bênh viên Đai hoc Y Dướ TPHCM

Chịu trách nhiệm chính: Nông Hữu Thọ

Email: huuthomd@gmail.com

Ngày nhâan bài: 10/1/2021

Ngày phản biên khoa hoc: 9/2/2021

Ngày duyệt bài: $5 / 3 / 2021$

\section{TREATMENT FOR ACUTE AORTIC SYNDROME}

Objectives: The aim of this study was to evaluate the operative treatment of the acute aortic syndrome. Materials and methods: A prospective descriptive study was conducted in a series of patients, suffering the acute aortic syndrome, in Cho Ray hospital and University Medical Centerfrom September 2015 to September 2018. Results: There are 102 patients suffering AAS but 101 patients were performed surgery with a mean age of $46.3 \pm 21,78$ males $(78.7 \%)$ and 23 females $(23.2 \%)$. The early mortality of operative treatment of AAS were $22,7 \%$ (23/101). Etiology of death was as follows: low cardiac output (4/23); stroke, (5/23); hemorrhage, (2/23); sepsis, $(2 / 23)$; and varied other causes (10/23). Plots of Kaplan-Meier estimates of survival of this group of patients are $69 \%$. Conclusion: Operative mortality in this result of surgical treatment for AAS is similar to contemporary worldwide registry data. Rateof deaths after surgery for AASare 22,7\% (23/101), arising from postoperative stroke, hemorrhage, or cardiac dysfunction and pneumonia.Plots of Kaplan-Meier estimates of survival of this group of patients are $69 \%$. A further understanding of the mechanisms of AAS in this population is needed.

Keywords: Acute aortic syndrome (AAS), aortic dissection (AD), aortic intramural hematoma (IMH), penetrating atherosclerotic ulcer (PAU), aortic aneurysmal rupture (AAR).

\section{I. ĐĂT VẤN ĐỀ}

Hội chứng ĐMC cấp là một khái niệm khá cập nhật trong giai đoạn hiện nay và được xếp vào nhóm bệnh cảnh cấp cứu của ĐMC ngực, bao gồm một số thể thường gặp như: bóc tách kinh điển (A.D), máu tụ trong thành (IMH), loét thủng xuyên thành (PAU) và phình $Đ M C$ ngực dọa võ [1],[3]. Trong HS-PT tim, đây là nhóm bệnh cảnh nặng, bởi diễn tiến nhanh và tỷ lệ tử vong khá cao nếu không được xử trí kịp thời[2]. Nếu không điều trị, tỷ lệ tử vong là $50 \%$ trong 48 giờ đâu, $80 \%$ trong 2 tuần đâu và $92 \%$ trong 1 năm. $[5,7]$ Mặc dù đã có nhiều tiến bộ về chẩn đoán giúp phát hiện nhanh và xử trí sớm nhưng công tác điêu trị HC ĐMC cấp hiện vẫn còn nhiều khó khăn và thử thách. 
Trong bối cảnh ở Việt Nam hiện nay, số lượng các công trình nghiên cứu tập trung chuyên sâu về $\mathrm{HC}$ ĐMC vẫn còn khá khiêm tốn. Do vậy, chúng tôi tiến hành đề tài này nhằm đánh giá kết quả điều trị phẫu thuật ở nhóm bệnh nhân nghiên cứu có hội chứng động mạch chủ ngực cấp, đồng thời ghi nhận tần suất xuất hiện các biến chứng cũng như tỷ lệ sống còn trong suốt thời gian theo dõi.

\section{II. ĐỐI TƯỢNG VÀ PHƯƠNG PHÁP NGHIÊN CỨU}

2.1. Đối tượng nghiên cứu. Các bệnh nhân được chẩn đoán một trong các thể của hội chứng động mạch chủ ngực cấp tính, được nhập viện và điều trị phẫu thuật tại khoa phẫu thuật tim bệnh viện Chợ Rẫy và khoa Phẫu thuật tim mạch, Bệnh viện Đaai Học Y Dược trong thời gian từ tháng $9 / 2015$ đến $9 / 2018$ thỏa mãn các tiêu chí chọn mẫu.

\subsection{Phương pháp nghiên cứu}

Thiết kế nghiên cứu mô tả dọc tiến cứu.

2.3. Xử lý số liệu. Các thông tin về hành chính và các số liệu nghiên cứu được nhập vào máy tính theo mã số bênh nhân đã được mã hóa, và được xử lý bằng phần mềm thống kê y học SPSS 26.

\section{KẾT QUẢ NGHIÊN CỨU}

\section{1. Đặc điểm chung của nhóm bệnh} nhân nghiên cứu

- Đặc điểm về giới. Số lượng bệnh nhân nam cao hơn nữ gấp 3,4 lần với tỷ lệ nam (78/101) $77,2 \%$ và tỷ lệ nữ (23/101) 22,8\%

- Đăc điểm tuổi và nhóm tuối của nhóm nghiên cứu. Tuổi trung bình của nhóm $B N$ nghiên cứu là $54,1 \pm 14,9$. Trong đó có bệnh nhân trẻ tuổi nhất là 20 tuổi, bệnh nhân lớn tuổi nhất là 79 tuổi.

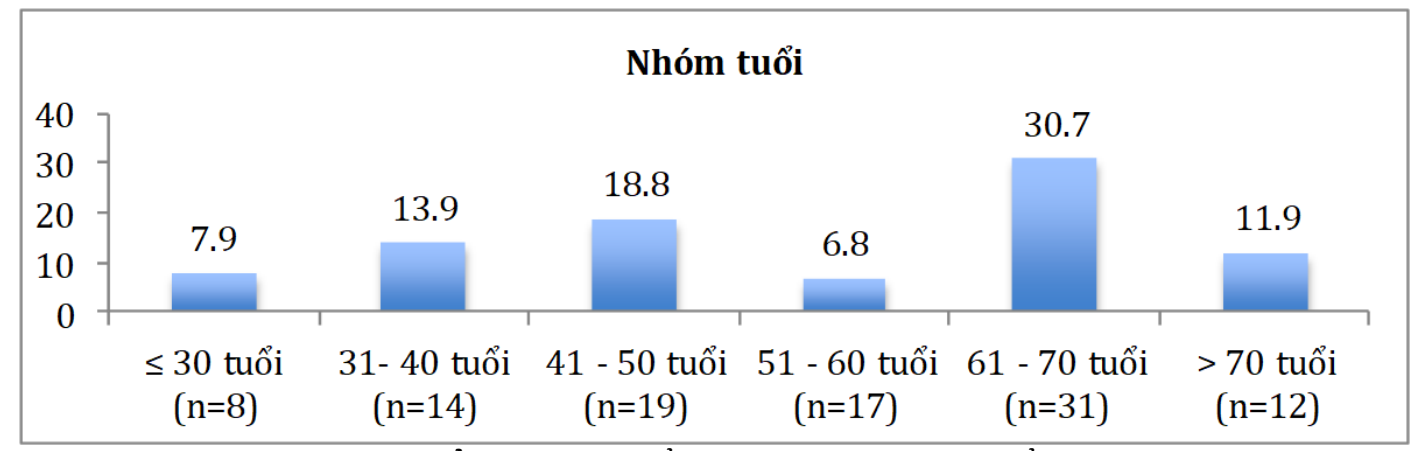

Biểu đồ 3.1: Biểu đồ phân bố nhóm tuồl

\section{2. Đặc điểm phẫu thuật hội chứng ĐMC ngực câp theo loại tổn thương}

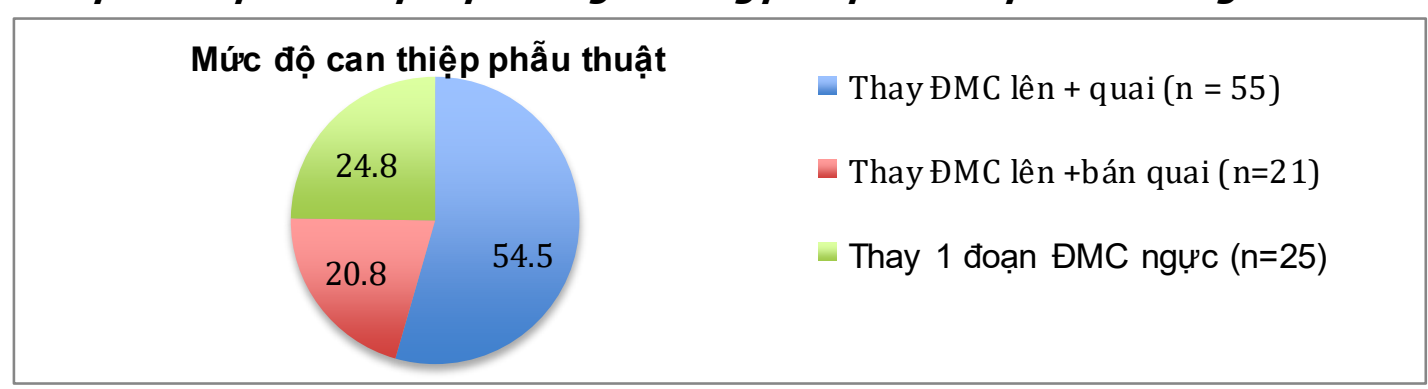

Biểu đồ 3.2. Mức độ can thiệp phẫu thuật trong hội chứng ĐMC ngực cấp (n=101)

Nhận xét: Trong hội chứng ĐMC cấp, ghi nhận tỉ lệ thay ĐMC ngực lên + quai là cao nhất chiếm $54,5 \%$. Điêu này tương tự ở các loại tổn thương: bóc tách, huyết khối thành và loét thủng với tỉ lệ lần lượt là $52,2 \%, 62,5 \%$ và $77,8 \%$. Nhóm phình ĐMC doạ vơ, mức độ can thiệp thay một đoạn ĐMC chiểm tỉ lệ chủ yếu là $65 \%$.

Bảng 3.1. Đặc điểm phẫu thuật theo từng loại tổn thương

\begin{tabular}{|c|c|c|c|c|c|}
\hline \multicolumn{2}{|c|}{} & $\begin{array}{c}\text { Bóc tách kinh } \\
\text { điển( } \mathrm{N}=46)\end{array}$ & $\begin{array}{c}\text { Loét } \\
\text { thủng( } \mathrm{N}=9)\end{array}$ & $\begin{array}{c}\text { Huyết khối } \\
\text { thành( } \mathrm{N}=24)\end{array}$ & $\begin{array}{c}\text { Phình doa } \\
\text { vỡ }(\mathrm{N}=20)\end{array}$ \\
\hline \multirow{2}{*}{$\begin{array}{c}\text { ĐMC ngực } \\
\text { đoạn lên }\end{array}$} & $\begin{array}{c}\text { Phấu thuật đoạn lên đơn } \\
\text { thuần }\end{array}$ & $5(10,9 \%)$ & $0(0,0 \%)$ & $2(8,3 \%)$ & $5(25,0 \%)$ \\
\cline { 2 - 6 } & \begin{tabular}{c} 
Phâ̂u thuật Bentall \\
\cline { 2 - 6 }
\end{tabular} & $2(4,3 \%)$ & $0(0,0 \%)$ & $0(0,0 \%)$ & $1(5,0 \%)$ \\
\hline
\end{tabular}




\begin{tabular}{|c|c|c|c|c|c|}
\hline \multirow{2}{*}{$\begin{array}{l}\text { ĐMC ngực } \\
\text { lên+Bán } \\
\text { quai }\end{array}$} & Phẩu thuật bán quai & $6(13,0 \%)$ & $2(22,2 \%)$ & $6(25,0 \%)$ & $0(0,0 \%)$ \\
\hline & $\begin{array}{c}\text { Phấu thuật Bentall+bán } \\
\text { quai }\end{array}$ & $7(15,2 \%)$ & $0(0,0 \%)$ & $0(0,0 \%)$ & $0(0,0 \%)$ \\
\hline \multirow{3}{*}{$\begin{array}{l}\text { ĐMC ngực } \\
\text { lên } \\
+ \text { quai }\end{array}$} & Phấu thuật quai & $16(34,8 \%)$ & $7(77,8 \%)$ & $13(54,2 \%)$ & $2(10,0 \%)$ \\
\hline & Phấu thuật Tirone + quai & & & & \\
\hline & Phấu thuật Bentall + quai & $6(1$ & & & $5(2)$ \\
\hline \multicolumn{2}{|c|}{ ĐMC ngực đoạn xuốngđđơn thuần } & $0(0,0 \%)$ & $0(0,0$ & $0(0,0 \%)$ & $5(25,0 \%)$ \\
\hline \multicolumn{2}{|c|}{ Phấu thuật hybrid } & $3(6,5 \%)$ & $2(22,2 \%)$ & $3(12,5 \%)$ & $0(0,0 \%)$ \\
\hline \multicolumn{2}{|c|}{ Thời gian phấu thuật (giờ) } & $7,6 \pm 1,6$ & $7,3 \pm 2,9$ & $7,6 \pm 2,4$ & $7,8 \pm 3,0$ \\
\hline \multicolumn{2}{|c|}{ Thời gian CPB (phút) } & & & 19, & 231,8 \\
\hline \multirow{2}{*}{\multicolumn{2}{|c|}{ Thời gian kẹp ĐM chủ (phút) }} & 156 & & 122, & $153,9 \pm 110,2$ \\
\hline & & $44(95,7 \%)$ & $9(100,0 \%)$ & $24(100,0 \%)$ & $14(70,0 \%)$ \\
\hline \multicolumn{2}{|c|}{ Thời gian ngưng tuần hoàn (phút) } & $37,1 \pm 17,6$ & $35,2 \pm 9,2$ & $44,5 \pm 25,4$ & $41,6 \pm 19,4$ \\
\hline
\end{tabular}

Nhận xét: Ở nhóm bóc tách ĐMC chủ ngực, phẫu thuât đi kèm theo chủ yếu là Bentall và Ticron nhằm sửa chữa van và gốc ĐMC ngực. Ghi nhận có 6,5\% TH có kết hợp đặt stent ĐMC ngực đoạn xuống. Thời gian phẫu thuật trung bình của các loại tổn thương gân tương đương nhau, thấp nhất là nhóm loét thủng 7,3 giờ và dài nhất là nhóm phình $Đ M C$ doạ vỡ 7,8 giờ. Ghi nhận đa phần đều có ngưng tuần hoàn trong lúc mổ, nhóm loét thủng và huyết khối thành có tỉ lệ ngưng tuần hoàn là $100 \%$. Mức độ hạ thân nhiệt vừa được sử dụng trong hầu hết các loại tổn thương.

3.3. Tử vong và biến chứng trong thời gian nằm viện:

\subsubsection{Tử vong trong thời gian nằm viện}

\section{Kết quả điều trị}

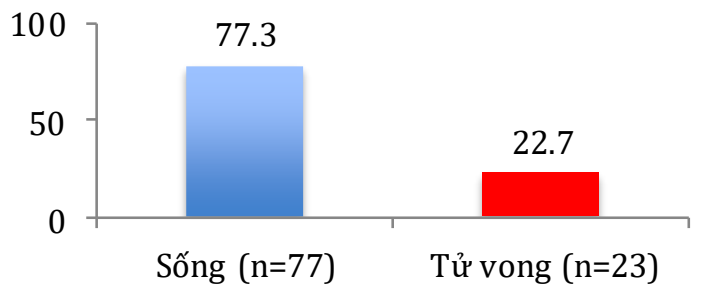

Biểu đô 3.3. Tỉ lệ tử vong trong thời gian nằm viện
Nhận xét: Tỉ lệ tử vong trong thời gian nằm viện của nghiên cứu là $22,7 \%(23 / 101)$

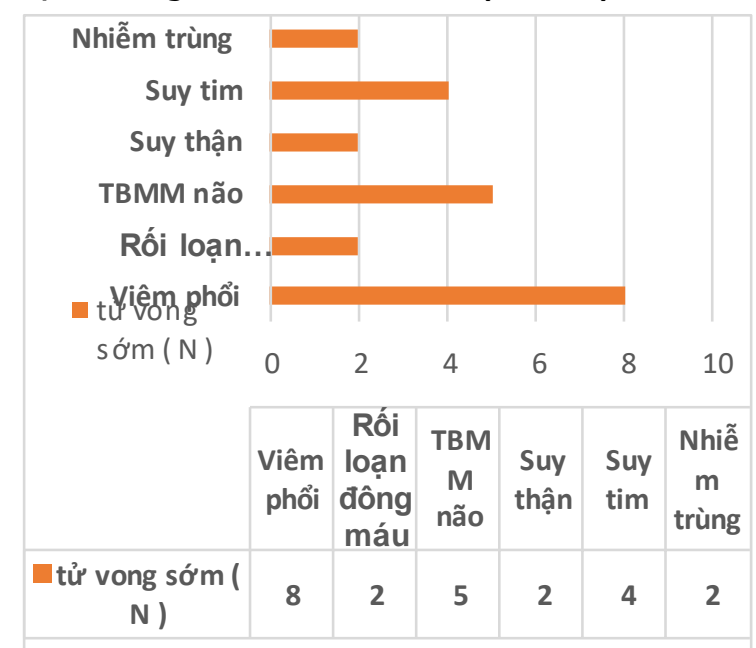

Tử vong sớm và các nguyên nhân

Biểu đồ 3.4. Nguyên nhân tử vong trong viện

Nhận xét: Nguyên nhân tử vong trong viện thường gặp là viêm phổi $8 / 24$ và TBMMN chiếm 5/23; Suy tim do giảm cung lượng 4/23 trường hợp.

\subsubsection{Biến chứng hậu phẫu}

Suy đa co quan $(n=12)$ Nhiễm trùng vết mổ $(n=19)$ Biến chứng suy thận (n=19)

Thở máy kéo dài $(n=13)$

Nhồi máu cơ tim ( $n=3)$

Chảy máu (n=15)

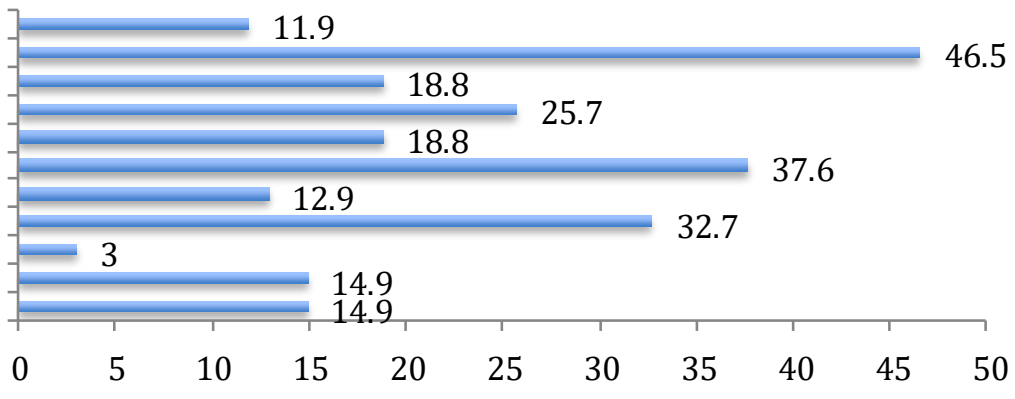

Biểu đồ 3.5. Biểu đồ biến chứng hậu phẫu 
Nhận xét: Biến chứng viêm phổi chiếm $37,6 \%$ sau mổ; có $12,9 \%$ BN thở máy kéo dài trên 30 ngày do biến chứng viêm phổi.Biến chứng chảy máu sau mổ chiếm $14,9 \%$. Tất cả những $\mathrm{TH}$ này đều được mổ lại lần 2 cầm máu và làm sạch khoang trung thất. Biến chứng nhiễm trùng vết mố chiếm $18,8 \%$. Không ghi nhận trường hợp nào để hở xương ức. Biến chứng TBMMN chiếm tỉ lê $25,7 \%$.

\subsection{Kết quả theo dõi xa}

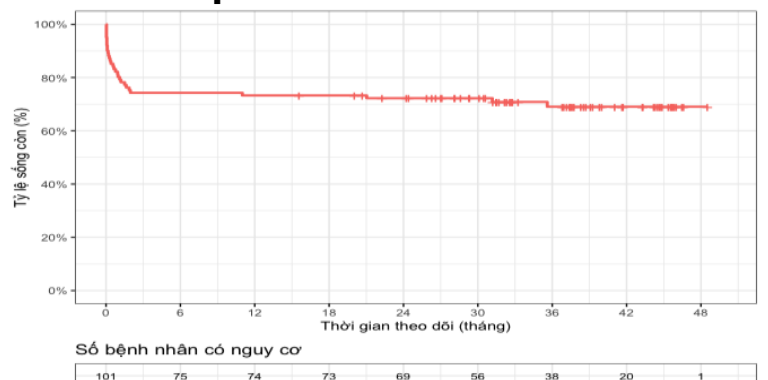

Biêu đồ 3.6. Đường cong Kaplan-Meier về tỷ lệ sông còn của nghiên cứu

Nhận xét: Thời gian theo dõi trung bình của BN trong nghiên cứu là: 31,2 tháng (ngắn nhất là 2 tháng và dài nhất là 39,3 tháng). Ghi nhận có: 8 trường hợp mất dấu theo dõi. và 7 trường hợp tử vong trong suốt thời gian theo dõi. Tỉ lệ sống còn của nghiên cứu theo Kaplan - Meier: 69\%.

\section{BÀN LUẬN}

Báo cáo của hội tim mạch Châu Âu về chẩn đoán và điều trị bệnh lý ĐMC chủ cho thấy theo Phân tích của hội về bệnh lý ĐMC toàn câu năm 2010, tần suất phình ĐMC ngực và bóc tách
ĐMC ngực gia tăng từ 2,49/100,000 dân đến 2,78/100,000 dân từ năm 1990 đến năm 2010, tỉ lệ nam giới chiếm đa số.

Tác giả Harnandez - Vaquero và cộng sự [4,5] đánh giá kết quả phẫu thuật cho 738 BN bị phình ĐMC ngực lê cho thấy tuối trung bình là $65,27 \%$ và nam giới chiếm $68,56 \%$. Tác giảthấy có $52,3 \% \mathrm{BN}$ có cần phải thay van ĐMC kèm theo trong lúc phẫu thuât ĐMC ngực lên, $18,97 \%$ BN có cần phẫu thuật sửa chữa gốc ĐMC, $11,65 \%$ BN chỉ cần thay 1 đoạn ĐMC ngực lên và 4,07\% cần phẫu thuật tới vùng quai ĐMC.

Tác giả Goodney báo cáo tổng hợp các nghiên cứu về phẫu thuật phình ĐMC ngực đoạn xuống cho thấy lâm sàng của 1008 BN phình ĐMC ngực đoạn xuống vỡ: tuổi trung bình 76, nam giới chiếm $53,7 \%$, tỉ lệ nhồi máu cơ tim là $5,45 \%$, tỉ lệ bệnh lý mạch máu não là 5,35\%, bệnh phổi tắc nghẹn mạn tính là 13,09\%. Tác giả nhận thây tỉ lệ tràn máu màng phối trái trong vỡ ĐMC chủ ngực xuống được phát hiên trên Xquang ngực thẳng là $53,2 \%$ và trên chụp CLĐT là $76,4 \%$.

Nghiên cứu chúng tôi có thời gian theo dõi trung bình là 31,2 tháng, ngắn nhất là 2 tháng và dài nhất là 39,3 tháng. Ghi nhận có $8 \mathrm{TH}$ mất dấu theo dõi và 7 trường hợp tử vong trong thời gian theo dõi. Tỉ lệ sống còn của nghiên cứu là 69\%. Cụ thể: tỉ lệ sống còn của từng loại tổn thương:

- Tỉ lệ sống còn bóc tách ĐMC là: $69,5 \%$

- Tỉ lệ sống còn huyết khối thành là: $71,3 \%$

- Tỉ lể sống còn phình ĐMC doa vỡ là : $70 \%$

- Tỉ lệ sống còn loét thủng/ thủ thuật là: $72,2 \%$

Bảng 3.2. So sánh tỉ lệ sông còn của các tác giả[6,7]

\begin{tabular}{|c|c|}
\hline Tác giả & Tỉ lệ sống còn \\
\hline Chúng tôi & $\begin{array}{l}\text { Tỉ lệ sống còn bóc tách ĐMC là: } 69,5 \% \\
\text { Tỉ lệ̂ sống còn huyết khối thành ĐMC là: } 71,3 \% \\
\text { Tỉ lể sống còn phình ĐMC doa võ là: } 70 \% \\
\text { Tỉ lể sống còn loét thủng/ thủ thuất ĐMC là: } 72,2 \%\end{array}$ \\
\hline Olsson cs, 2017 & Bóc tách ĐMC ngực: năm 1: 95\%; 5 năm: 86\%; 8 năm: 76\% [6] \\
\hline Pan và CS, 2018 & $\begin{array}{l}\text { Phình và bóc tách ĐMC ngực: } 5 \text { năm: } 86,7 \% ; 10 \text { năm: } 77,6 \% ; 20 \text { năm: } \\
52,1 \% ; 30 \text { năm: } 38,3 \% ; 40 \text { năm: } 26,7 \%\end{array}$ \\
\hline Song và CS, 2009 & Huyết khôii thành ĐMC năm 1: 87,6\%; 2 năm: 84,9\%; 3 năm: 83,1\% \\
\hline Tian và cs,2019 & $\begin{array}{l}\text { Huyết khối thành ĐMC }(\mathbf{n = 3 4 3 )} \\
\text { năm 1: } 91,8 \% ; 2 \text { năm: } 90,2 \% ; 3 \text { năm: 89,2\%; năm 5: 87,7\% [7] }\end{array}$ \\
\hline Matsushita, 2016 & $\begin{array}{l}\text { Huyết khối thành ĐMC (n=121): năm 1: 99,1\%; } 3 \text { năm: } 95,3 \% \\
\text { Bóc tách ĐMC ngực }(\mathbf{n}=339) \text { năm 1: } 96,2 \% ; 3 \text { năm: 89,1\%; năm 5: 83,6\% } \\
(p=0,29)\end{array}$ \\
\hline Goodney, 2011 & Phình ĐMC ngực võ̃/doạ vỡ : năm 1: 87\%\%; năm 5: 72\%\% \\
\hline
\end{tabular}

Năm 2018, Tác giả Pan và cộng sự báo cáo 47 năm kinh nghiệm phẫu thuật động mạch chủ ngực đoạn lên với 614 BN (33,7\% bóc tách,
$66,3 \%$ phình), sau khi đã loai ra các $\mathrm{TH}$ tử vong trong vòng 30 ngày, cho thẩy tỉ lệ sống cỏn của nhóm nghiên cứu là $86,7 \%, 77,6 \%, 52,1 \%$, 
$38,3 \%$ và $26,7 \%$ ở các thời điểm theo dõi 5,10 , 20,30 và 40 năm.

Chúng tôi nhận thấy tỉ lệ sống còn trong nghiên cứu tương đương với các nghiên cứu của các tác giả khác. Trong thời gian theo dõi, chúng tôi chỉ có $7 \mathrm{TH}$ tử vong thêm chiếm $8,8 \%$. Đa phần các $B N$ sau phẫu thuật đều ổn định và có chất lượng sống tốt.

\section{KẾT LUÂ̂N}

HC ĐMC là một cấp cứu ngoại khoa, cần được chẩn đoán sớm và xử trí kịp thời. Phẫu thuật trên $\mathrm{DMC}$ vẫn còn là một cuộc mổ nặng kéo dài, nhiều nguy cơ và tỷ lệ biến chứng sau mổ. Phân tầng xử trí tổn thương và xác định được phạm vi can thiệp có vai trò quan trọng. Trong nghiên cứu này, tỷ lệ thay $Đ M C$ lên và quai chiếm tỷ lệ nhất $(54,5 \%)$; thay ĐMC lên và bán quai chiếm tỷ lệ ít nhất $(20,8 \%)$. Tỷ lệ tử vong sớm trong thời gian nằm viện là: $22,7 \%$ (23/101). Kết quả trung hạn: thời gian theo dõi trung bình là 32,2 tháng ghi nhận: có 8 trường hợp mất dấu theo dõi và có thêm $7 \mathrm{TH}$ tử vong. Tỳ lệ sống còn của nghiên cứu theo đồ thị Kaplan - Meier là: $69 \%$

\section{TÀI LIỆ THAM KHẢO}

1. Phạm Tho Tuấn Anh (2008), "Đặc điểm kỹ thuật phẫu thuật vùng quai động mạch chủ".Y học Thành phố Hồ Chí Minh, 13, pp. tr. 1-9.

2. Lâm Triêuu Phát, Nguyê̂n Thái An, Trân Quyết Tiến, Pham Tho Tuấn Anh, Ngố Tuấn Anh, (2014), "Kết quả bước đầu đặt ống ghép nội mach trong điều trị phình động mạch chủ ngực,". Tạp chí Y Dược Lâm Sàng 108, 9 (số 1), pp. 82-87.

3. Colli A., Carrozzini M., Galuppo M., Comisso M., Toto F., et al. (2016), "Analysis of early and long-term outcomes of acute type A aortic dissection according to the new international aortic arch surgery study group recommendations". Heart Vessels, 31 (10), pp. 1616-24.

4. Hernandez-Vaquero $D_{\text {., }}$ Silva J., Escalera A. et al (2020) Life expectancy after Surgery for Ascending aortic aneurysm, J Clin Med, 615 (9): pp. 1-13. doi:10.3390/jcm9030615.

5. Gudbjartsson Tomas, Ahlsson Anders, Geirsson Arnar, Gunn Jarmo, Hjortdal Vibeke, et al. (2020), "Acute type A aortic dissection - a review". Scandinavian Cardiovascular Journal, 54 (1), pp. 1-13.

6. Olsson Christian, Ahlsson Anders et al. (2017), "Medium-term survival after surgery for acute Type A aortic dissection is improving". European Journal of Cardio-Thoracic Surgery, 52 (5), pp. 852-857.

7. Tian D.H., Chakos A., Hirst L., et al (2019) Surgery for type A intramural hematoma : a systematic review of clinical outcomes, Ann Cardiothorac Surg , 8 (5): pp. 518 -523.

\section{ĐÁNH GIÁ KẾT QUẢ SỬ DUUNG CÁC DANG VAT ĐÙI TRƯớC NGOÀI TỰ DO TRONG TẠO HİNH KHUYẾT PHẦN MỀM BÀN TAY}

\section{TÓM TẮT}

Mục tiêu: Đánh giá kết quả sử dụng các dang vat đùi trước ngoài (ĐTN) tự do trong tạo hình khuyết phần mềm (KPM) bàn tay. Đối tượng và phương pháp nghiên cứu: 45 bệnh nhân $(B N)$ có khuyết phần mềm vùng bàn tay với 47 vạt ĐTN tự do được sử dụng trong thời gian từ tháng 7/2007 đển 6/2020, tại Bệnh viện đa khoa Xanh Pôn. Kết quả: có 40 vạt sống hoàn toàn, 3 vạt thiểu dưỡng, hoại tử mép vạt; 2 vạt hoại tử đâu xa vạt, 2 vạt hoại tử một phân vạt. Các dạng vạt ĐTN được sủ dụng bao gồm: 6 vạt da cân, 41 vạt da mõ trong đó có 38 vạt được làm mỏng, 26 vạt được làm mỏng vi phẫu tích; 12 vạt được sử dụng dưới dạng vạt chùm. Kết quả tạo hình đạt yêu cầu về chức năng và thẩm mỹ. Kết luận: vạt đùi

\section{*Bênh viện Xanh Pôn}

**Trướng ĐH Y Hà Nôi

Chịu trách nhiệm chính: Nguyễn Vũ Hoàng

Email: nvuhoangmd@gmail.com

Ngày nhân bài: 2/1/2021

Ngày phản biên khoa hoc: 3/2/2021

Ngày duyệt bài: 26/2/2021
Nguyễn Vũ Hoàng*, Trần Thiết Sơn**

trước ngoài tự do là một lựa chọn đáng tin cậy trong tao hình cho các khuyết tổ chức vùng bàn tay.

Tư khóa: Vạt đùi trước ngoài, khuyết phân mềm, phẫu thuật bàn tay.

\section{SUMMARY}

\section{EVALUATION OF THE USING ANTEROLATERAL THIGH FREE FLAP FOR HAND RECONSTRUCTION}

Objectives: The aim of this study was to evaluate the results of free anterolateral thigh (ALT) flap reconstruction for soft tissue defects of hand. Patients and methods: 47 ALT flaps have been raised in 45 patients with soft tissue defects of the hand after trauma, burn, or severe scar contracture release....These patients underwent surgery at the Department of plastic and reconstructive surgery, SaintPaul hospital (Ha Noi, Viet Nam), between July 2007 to June 2020. Results: 40 flaps were complete survival, 3flaps have marginal necrosis, 2 flaps have partial distal necrosis, 2 flaps have partial necrosis. There were 6 fasciocutaneous and 41 cutaneous flaps, 38 flaps were thinned and 26 flaps were thinned by 